\title{
THE AGE OF CHILDREN WHEN GROWTH IN STATURE CEASES
}

\author{
BY \\ E. M. B. CLEMENTS \\ From the Department of Anatomy, University of Birmingham
}

(RECEIVED FOR PUBLICATION DECEMBER 7, 1953)

The age at which the children in a community reach adult stature is usually determined from an estimation of the upper limit of the distribution of the age at which growth in height ceases. The mean statures for different age-groups are examined, and the age at which the upward trend in the mean values stops is taken as the upper limit of the distribution. Neither the mean age nor the standard deviation of the distribution can be obtained from such "crosssectional' data, and estimates depending upon the concept of an upper limit to a distribution are unsatisfactory for statistical reasons. However, these objections do not arise in the analysis of 'longitudinal' data, that is, observations on the same individuals recorded over a period of several years. In a survey of this kind, Morant (1952) found that $15.3 \%$ of Royal Air Force apprentices reached adult stature by their eighteenth birthday, and $32 \cdot 1 \%$ by their nineteenth birthday. In the following paper, corresponding data for present-day school boys and girls are analysed.

\section{Data}

The records were placed at our disposal by the authorities of two independent or public schools in England, and it can be taken that the children concerned came from families in the upper income group of the community. The measurements were recorded at medical examinations of boys made in the period 1949 to 1952, and of girls during the period 1945 to 1952 . Records of the stature of 75 boys until they were at least 18 years 6 months old were available. They were measured to the nearest quarter of an inch at the same time of the day and without clothing, at four-monthly intervals. Similar data for 67 girls, measured annually to the nearest oneeighth of an inch in gym clothing without shoes, were available until they were at least 17 years 7 months old. The anthropometers used in both series of measurements were of the type attached to weighing machines.

\section{Analysis}

The measurements of each child were charted and the records sorted into two groups; in one, growth in stature occurred between each examination, whereas in the other no increments were found for varying intervals of time. A detailed examination of the records in the latter group shows that two types of record occur. In the first, no further increase takes place during the period of observation, but in the second, after the stature has shown no change for some time, a further increase occurs. Figs. 1 and 2 show examples of the first type, and Figs. 3 and 4 of the second. It is difficult to define a practical standard which will determine when growth in stature has stopped, because the period of arrested growth in the second type of record may extend for two years or more. In this paper, growth is taken as complete for the boys when three similar consecutive measurements occur over a period of eight months, and for the girls when two consecutive measurements are recorded over a period of 12 months, differences of one-quarter of an inch or more being regarded as significant. Thirty-five boys and 26 girls continued growing until after the observations stopped, and 40 boys and 41 girls were classified as having stopped growing during the period of observation. In the latter group, the stature of 20 boys and 29 girls remained unchanged, and that of 20 boys and 12 girls showed an increase before the records stopped.

The age when growth is complete is taken to be midway between the last occasion when growth was in progress and the first occasion when it had stopped. In this way account is taken of the error introduced by grouping the data. For example, one girl grew until at 16 years 1 month her stature was 65 inches, and at both 17 years 1 month and 18 years 1 month it was 66 inches. Clearly she was growing at the age of 16 years 1 month and not at 17 years 1 month, so 16 years 7 months was taken as the age 


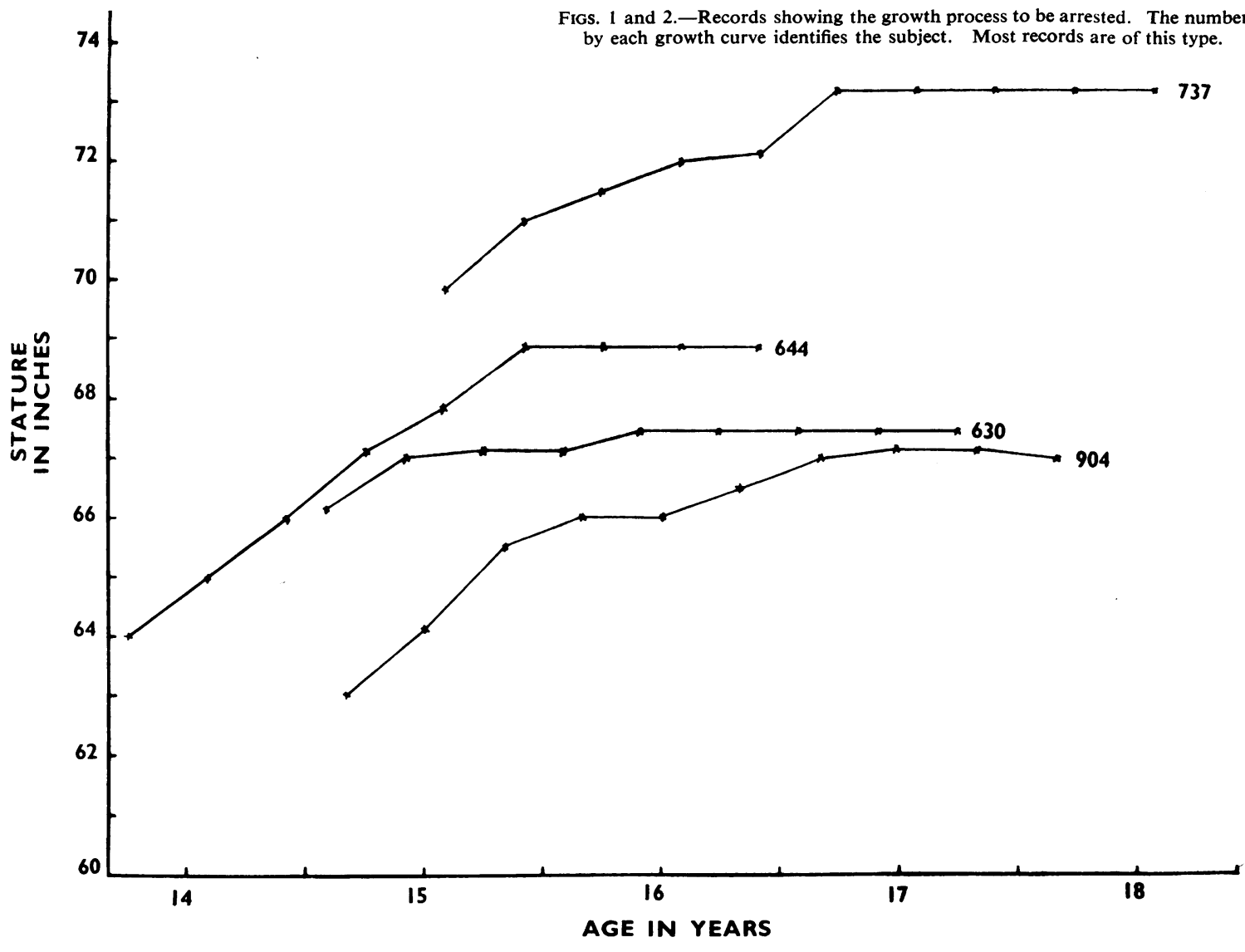

FIG. 1.

when growth in stature ceased. In this manner boys and girls, on the average, have the same stature for 10 and 18 months respectively before they are classified as having ceased to grow. It has been necessary to make this difference in the standard of classification for boys and girls, because of the limitations of the data, but in this case it will not invalidate the comparison of the results.

A few aberrant measurements were encountered. For example, some measurements were less than either the preceding or succeeding records, and occasionally a measurement was found to be larger than any later one recorded. These measurements have been attributed either to the effect of diurnal variation in stature, or to mistakes in technique, and have been disregarded.

The number of children in the samples who were still growing when the observations ceased have been combined with the observed frequencies of children who had stopped growing at earlier ages, and give a 'censored' distribution of the age at which growth in stature ceases. These censored data have been analysed by fitting a normal distribution by the method of Grundy (1952) and Hald (1952a and $b$ ).

\section{Results}

The observed frequencies of the age at which growth in stature stops in boys and girls are given in Tables 1 and 2 respectively. They are accompanied by the expected frequencies calculated on the assumption that the observations follow a normal (Gaussian) distribution. The agreement is good in both cases and statistical tests show that the observed frequencies do not deviate from the expected ones significantly $\left(\chi^{2}\right.$ for boys (d.f. 4$)=4 \cdot 8$ and for girls (d.f. 4$)=5 \cdot 8$ ). Thus the assumption that the observations follow a normal (Gaussian) distribution is a reasonable one. On the other hand, no observations exist in the upper part of the distribution, and complete data 


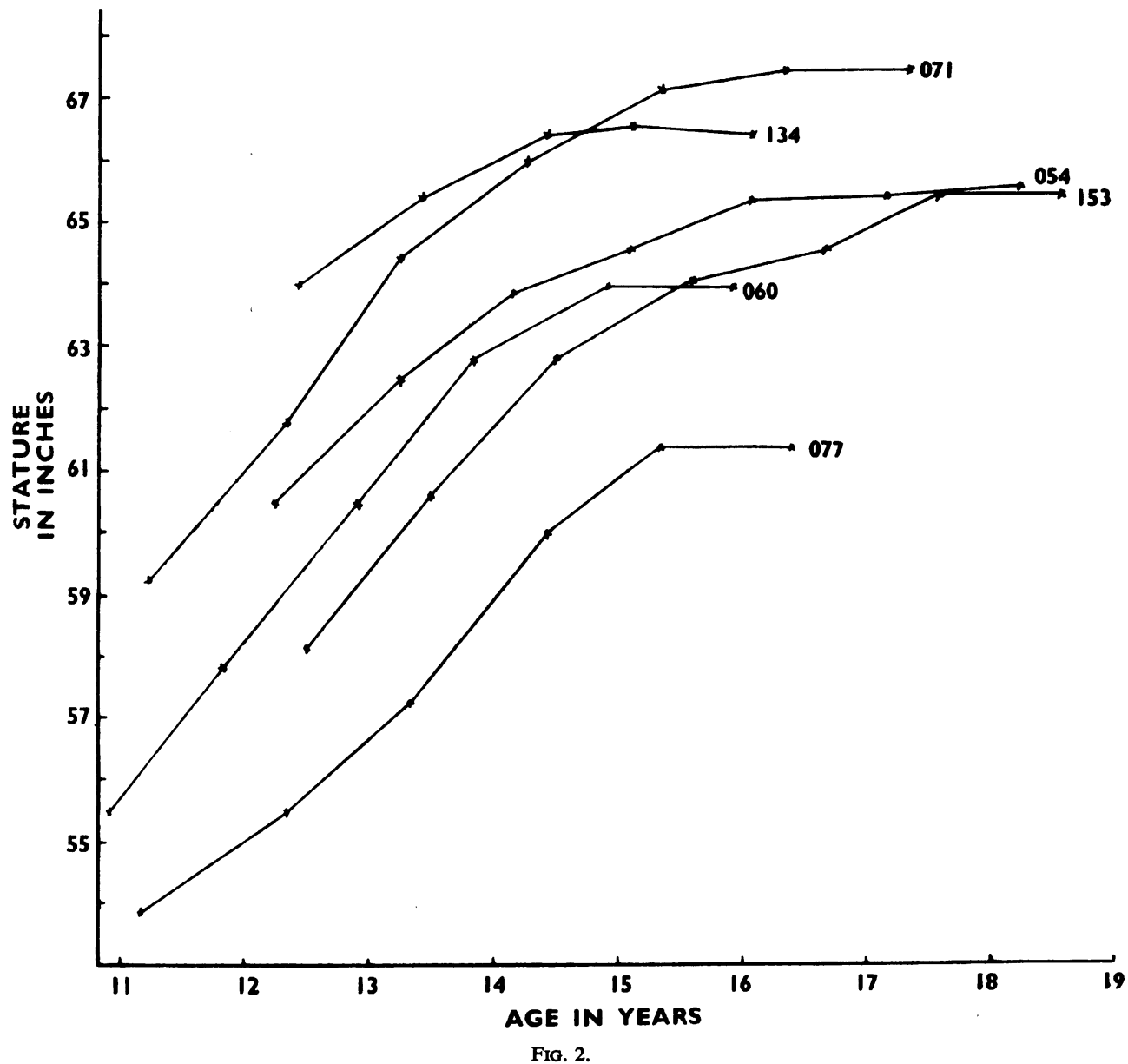

TABLE 1

TABLE 2

OBSERVED AND EXPECTED FREQUENCIES OF AGE WHEN BOYS REACH ADULT STATURE

\begin{tabular}{|c|c|c|c|c|}
\hline \multicolumn{3}{|c|}{ Age in Years and Months } & $\begin{array}{l}\text { Observed } \\
\text { Frequency }\end{array}$ & $\begin{array}{l}\text { Expected } \\
\text { Frequency }\end{array}$ \\
\hline 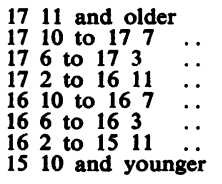 & $\begin{array}{l}\because \\
\because \\
\because \\
\because \\
\because \\
\therefore\end{array}$ & $\begin{array}{l}\because . \\
\cdots \\
\cdots \\
\cdots \\
\cdots\end{array}$ & $\begin{array}{r}35 \\
12 \\
11 \\
4 \\
8 \\
3 \\
2 \\
0\end{array}$ & $\begin{aligned} 34 \cdot 7 \\
11 \cdot 9 \\
10 \cdot 5 \\
7 \cdot 9 \\
5 \cdot 1 \\
2 \cdot 8 \\
1 \cdot 3 \\
0 \cdot 8\end{aligned}$ \\
\hline Total & .. & .. & 75 & $75 \cdot 0$ \\
\hline \multicolumn{3}{|c|}{$\begin{array}{c}\text { Number observed to cease growth during } \\
\text { period of observation }\end{array}$} & 40 & - \\
\hline
\end{tabular}

$\chi^{2}$ (d.f.4) $4 \cdot 8$

Mean 17 years 9.08 months s.d. 9.96 months

may show their frequency to be unusually high. If the distribution is skew with a long tail to the right, 
beyond the $50 \%$ point, the estimates, considered as estimates of medians, should not be affected.

The analysis of the observations shows that the mean age of boys when they stop growing is 17 years 9.08 months \pm 1.87 months and that the distribution has a standard deviation of 9.96 months. The corresponding age for girls is 16 years 2.71 months \pm 3.44 months and 13.62 months respectively. For example, $5 \%$ of the boys and girls are expected to have stopped growing before the age of 16 years $4 \cdot 75$ months, and 14 years $4 \cdot 37$ months respectively, and as few as $5 \%$ of them would be expected to be still growing after the age of 19 years 1.42 months and 18 years 1.05 months respectively.

\section{Discussion}

The foregoing analysis shows that girls on the average stop growing in stature 18.37 months before boys and this result is consonant with the generally recognized fact that girls mature physically at an earlier age than boys. It is evident that growth in stature stops in $90 \%$ of boys within a period of 2 years 8.67 months, and in $90 \%$ of girls within a period of 3 years 8.68 months, and it is clear that girls show a greater variation in the age at which adult stature is reached than boys.

The only means of comparing the results for present-day children with information about children 80 years ago, is by estimating the upper limit of the distribution, because all the earlier information is based on this limit. The ages by which $99 \%$ of boys and girls will be expected to have stopped growing have been taken as a practical approximation to this limit. These ages are 19 years $8 \cdot 29$ months and 18 years 10.44 months respectively for boys and girls. The upper limit of the distribution in the upper socio-economic group 80 years ago was about 20 years 6 months and 19 years 7 months for boys and girls respectively (British Association for the Advancement of Science, 1883) or about nine or $\mathbf{1 0}$ months later than it is now. We have no information about the sampling variation of these estimates, but the differences are sufficiently great for there to be little doubt that, on the average, individuals in the upper socio-economic group reach adult stature at an earlier age now than in the past. This conclusion is supported by other evidence, such as the recent finding that Scotsmen of every social class ceased growing in stature before their nineteenth year in 1941 (Clements and Pickett, 1952). The change may be attributed either to a general tendency for all children to mature at an earlier age, or to a selective change limited, for example, to a reduction in the frequency of older children who are still growing, and it is uncertain which of these factors is the more important one. Evidence such as the fact that children aged from 5 to 13 years show, on the average, an advance in development of from 18 months' to two years' growth during the last 80 years (Clements, 1953) supports the former

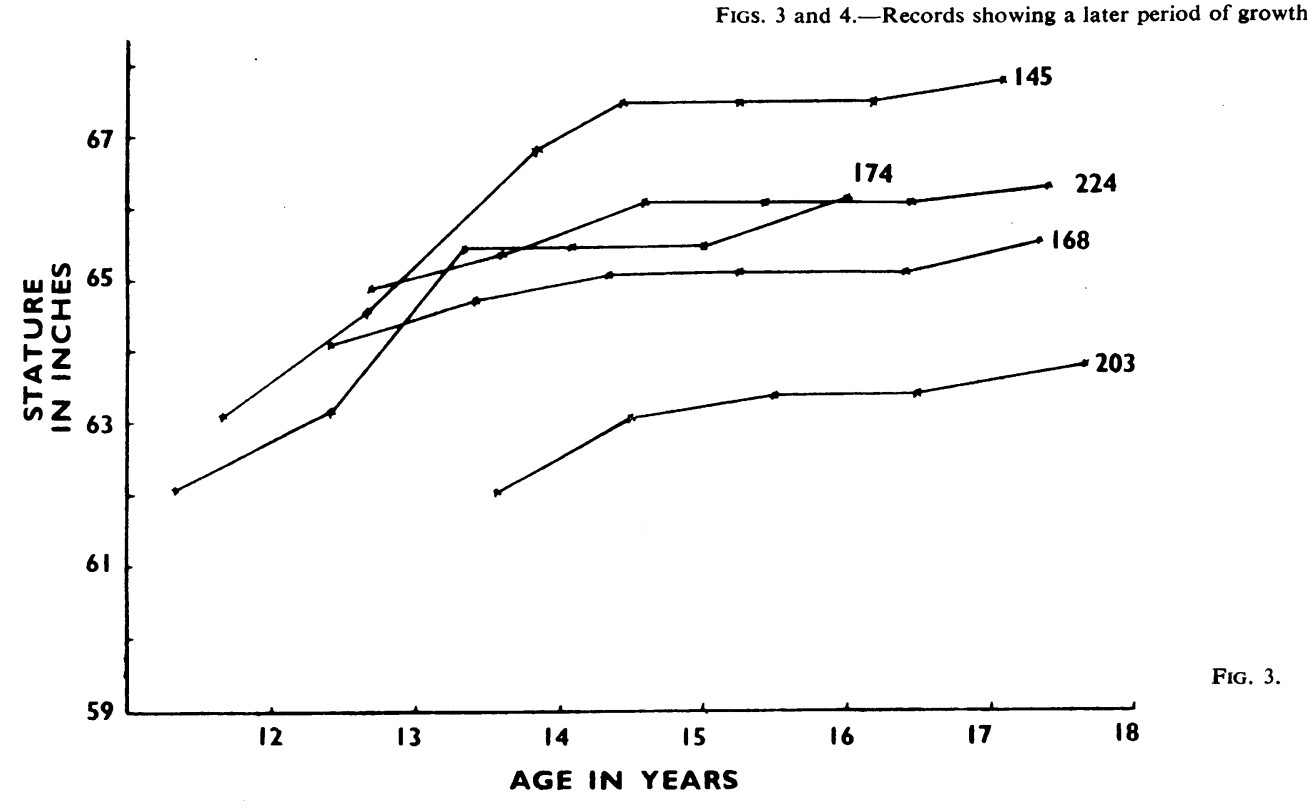




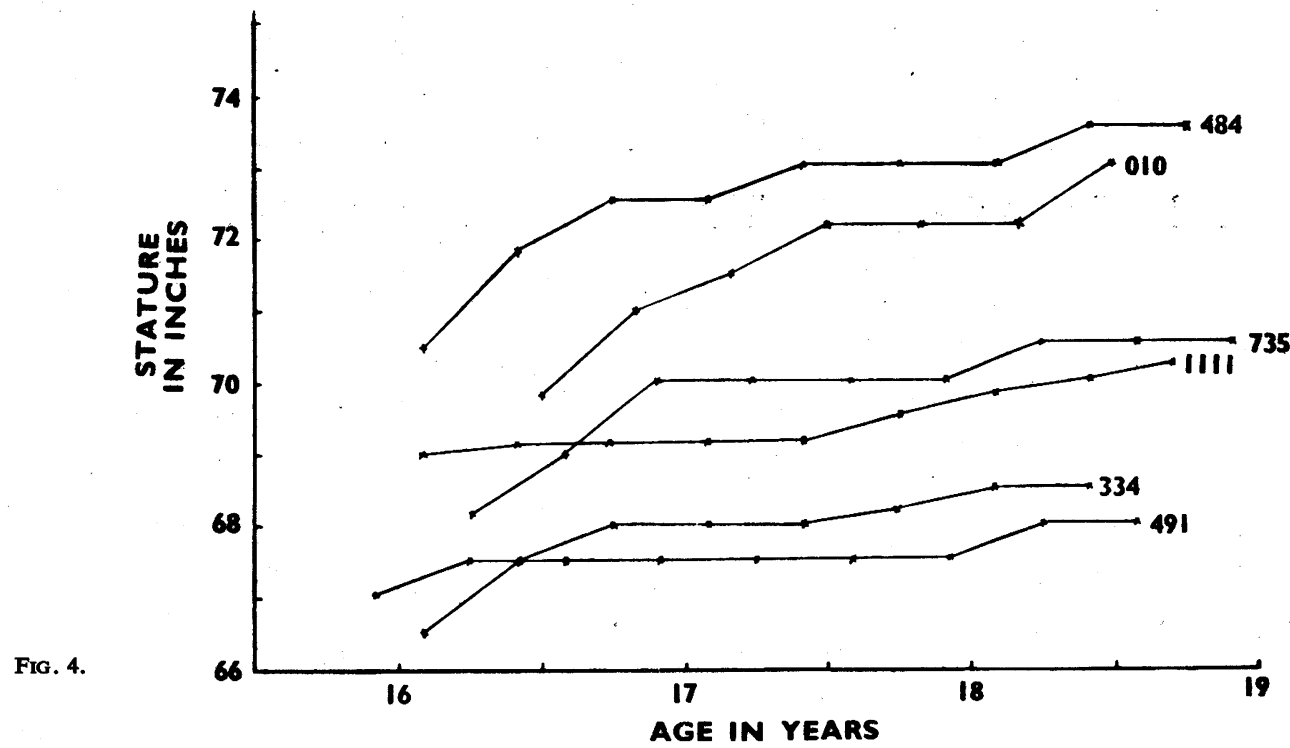

possibility, whereas the fact that growth in stature has been observed to begin again in a proportion of the older children following a long period of arrest - an observation also made by Morant (1952) favours the latter explanation.

There is little doubt that the tendency for growth in stature to stop at an earlier age is associated with the improvement which has taken place in living conditions. In addition to such an obvious factor in the growth of children as the state of their nutrition, more subtle factors tending to alter the constitution of the population, such as, for example, the reduced mortality of children now as compared with the past, and the smaller size of the average family, may all play some part.

\section{Summary}

Observations on the stature of 75 . boys and 67 girls, recorded at school over a period of years, have been analysed to determine the distribution of the age at which growth in stature ceases. The data for both sexes constitute censored normal distributions. The distribution for boys was found to have a mean age of 17 years 9.08 months \pm 1.87 months and a standard deviation of 9.96 months, and the corresponding estimates for girls are 16 years 2.71 months \pm 3.44 months and 13.62 months respectively.

I wish to thank the authorities of the two schools for making the records available to me, and the Medical Research Council for providing a grant. My thanks are also due to Dr. G. M. Morant and Mr. M. J. R. Healy for their very helpful criticism and advice.

\section{ReFrikencrs}

British Association for the Advancement of Science (1883). Final Report of the Anthropometric Committee. Rep. 53rd meeting Brit. Ass. Adv. Sci., Southport, 1883, p. 253. (Published 1884.) Clements, E. M. B. (1953). Brit. med. J., 2, 897. - and Pickett K G. (1952) Brit, J soc, Med, 6, 245.

Grundy, P. M. (1952). Biometrika, 39, 252.

Hald, A. (1952a). Statistical Theory with Engineering Applications. - (1952b). Statistical Tables and Formulas. New York.

Morant, G. M. (1952). Flying Personnel Research Committee Report. 711(f). 